\title{
Global genetic diversity of the Plasmodium vivax transmission-blocking vaccine candidate Pvs48/45
}

\author{
Andres F. Vallejo ${ }^{1}$, Nora L. Martinez' , Alejandra Tobon' ${ }^{1}$, Jackeline Alger², Marcus V. Lacerda ${ }^{3}$ Andrey V. Kajava ${ }^{4,5}$,
} Myriam Arévalo-Herrera ${ }^{6,7}$ and Sócrates Herrera ${ }^{6 *}$

\begin{abstract}
Background: Plasmodium vivax $48 / 45$ protein is expressed on the surface of gametocytes/gametes and plays a key role in gamete fusion during fertilization. This protein was recently expressed in Escherichia coli host as a recombinant product that was highly immunogenic in mice and monkeys and induced antibodies with high transmission-blocking activity, suggesting its potential as a P. vivax transmission-blocking vaccine candidate. To determine sequence polymorphism of natural parasite isolates and its potential influence on the protein structure, all pvs $48 / 45$ sequences reported in databases from around the world as well as those from low-transmission settings of Latin America were compared.
\end{abstract}

Methods: Plasmodium vivax parasite isolates from malaria-endemic regions of Colombia, Brazil and Honduras ( $n=60$ ) were used to sequence the Pvs $48 / 45$ gene, and compared to those previously reported to GenBank and PlasmoDB ( $n=222)$. Pvs48/45 gene haplotypes were analysed to determine the functional significance of genetic variation in protein structure and vaccine potential.

Results: Nine non-synonymous substitutions (E35K, Y196H, H211N, K250N, D335Y, E353Q, A376T, K390T, K418R) and three synonymous substitutions $(173, \mathrm{~T} 149, \mathrm{C156})$ that define seven different haplotypes were found among the 282 isolates from nine countries when compared with the Sal I reference sequence. Nucleotide diversity ( $\pi$ ) was 0.00173 for worldwide samples (range 0.00033-0.00216), resulting in relatively high diversity in Myanmar and Colombia, and low diversity in Mexico, Peru and South Korea. The two most frequent substitutions (E353Q: 41.9 \%, K250N: $39.5 \%$ ) were predicted to be located in antigenic regions without affecting putative B cell epitopes or the tertiary protein structure.

Conclusions: There is limited sequence polymorphism in pvs48/45 with noted geographical clustering among Asian and American isolates. The low genetic diversity of the protein does not influence the predicted antigenicity or protein structure and, therefore, supports its further development as transmission-blocking vaccine candidate.

\section{Background}

Malaria is an infectious parasitic disease caused by the genus Plasmodium which is transmitted by bites of infected Anopheles mosquitoes. Plasmodium falciparum and Plasmodium vivax are the two most common malaria parasites in humans, however differing in their

\footnotetext{
*Correspondence: sherrera@inmuno.org

${ }^{6}$ Caucaseco Scientific Research Center, Cali, Colombia

Full list of author information is available at the end of the article
}

clinical presentation and geographic distribution. Plasmodium falciparum causes the most severe symptoms and higher mortality, mainly among children under 5 years of age in Africa. Plasmodium vivax generally causes milder disease, is significantly less life-threatening [1] and is widely distributed in the Middle East, Asia, the Western Pacific, and Central and South America [2]. Despite global efforts to control malaria transmission resulting in a significant decrease in global incidence during the last decade, it continues to challenge public

\section{Biomed Central}

(c) 2016 Vallejo et al. This article is distributed under the terms of the Creative Commons Attribution 4.0 International License (http://creativecommons.org/licenses/by/4.0/), which permits unrestricted use, distribution, and reproduction in any medium, provided you give appropriate credit to the original author(s) and the source, provide a link to the Creative Commons license, and indicate if changes were made. The Creative Commons Public Domain Dedication waiver (http://creativecommons.org/ publicdomain/zero/1.0/) applies to the data made available in this article, unless otherwise stated. 
health systems, particularly in tropical countries. Current global malaria control strategies will greatly benefit from the development of an effective vaccine that interrupts malaria transmission among individuals of endemic communities [3, 4].

Proteins expressed by parasite sexual stages, namely gametocytes/gametes, could induce effective immune responses in the human host that would prevent gamete fertilization and zygote formation when ingested by the mosquito during a blood meal [5].

Plasmodium Ps $48 / 45$ proteins are expressed by male and female gametocytes/gametes during the parasite maturation process, and are therefore classified as prefertilization antigens [6]. These proteins belong to a family common to all Plasmodium species characterized by the presence of partially conserved domains containing six cysteine (Cys) amino acid residues that form one to three disulfide bridges, resulting in a specific tertiary structure $[7,8]$. In P. falciparum, this protein (Pfs48/45) is expressed on the surface membrane of gametocytes [9] and is required for male fertility [6]. In addition, Pfs $48 / 45$ is necessary for production of high antibody titers in individuals living in endemic areas $[10,11]$ that can reduce ookinete production and induce transmission-blocking activity [12-14]. It is currently considered a potential target for development as a transmission-blocking vaccine. As other proteins expressed on sexual forms, Pfs48/45 is rich in Cys residues, which has made it difficult to express as a recombinant product with proper conformation $[5,15]$. Pvs48/45, the homologous protein in $P$. vivax, was recently expressed in Escherichia coli and its immunogenicity was assessed in mice and Aotus monkeys. These studies indicated high immunogenicity in both animal models and the elicited antibodies displayed significant and reproducible transmission-blocking activity in ex vivo $P$. vivax membranefeeding assays (MFA) [9].

Genetic diversity could generate antigenic polymorphisms, which in turn could induce changes in critical epitopes and hamper vaccine efficacy. Successful development of an effective transmission-blocking vaccine is likely dependent on an assessment of the degree of genetic diversity in $p v s 48 / 45$ among $P$. vivax parasite populations in malaria-endemic locations [16]. Although available data indicate a limited Pvs48/45 genetic polymorphism on a regional scale $[17,18]$, knowledge of the sequence polymorphism on a broader scale and its potential impact on vaccine development is needed. Here, a total of 282 pvs $48 / 45$ sequences corresponding to parasites from eight countries from around the world were analysed for gene diversity to assess probable protein changes that could influence the immunogenicity and its vaccine potential.

\section{Methods}

\section{Ethics statement}

Blood samples used in this study were obtained from studies approved by the Institutional Review Board (IRB) of the Malaria Vaccine and Drug Development Center (MVDC) under the codes CIV-01-042009, CIV 08-102010 and CIV 009. Samples from volunteers were not linked to the identity of the donor. Written informed consent was obtained from each volunteer at enrolment. All volunteers were adults over 18 years of age.

\section{Origin of Plasmodium vivax samples}

The genetic diversity of $p v s 48 / 45$ was studied among $60 P$. vivax isolates from endemic regions of Brazil, Colombia and Honduras in Latin American (LA). The geographical origin of each of the LA isolates analysed in this study is listed in Table 1. Brazilian P. vivax isolates $(\mathrm{n}=13)$ were obtained from patients attending a tertiary healthcare centre in Manaus (Amazonas State) [19]; Colombian parasite samples $(n=35)$ were collected in four different malaria-endemic regions described elsewhere [20]; Honduran samples $(n=12)$ were collected at the University Hospital located in Tegucigalpa, and its origin was determined to seven different localities throughout the country. Additionally, a total of 222 sequences reported to the GenBank and PlasmoDB originally from South Korea [17], North Korea [18], India and Indonesia [18], Thailand and Vanuatu [21], Mexico, Peru, Thailand and Myanmar (Plasmodium vivax Hybrid Selection initiative, Broad Institute [22, 23], and reference sequences from Brazil, India, Mauritania, and North Korea were used for comparison.

\section{Extraction and purification of parasite genomic DNA}

Parasite genomic DNA was extracted from filter-paper blood spots using $10 \%$ Chelex 100 (Biorad, USA) and from EDTA-blood samples using the salting-out method [24], and were identified with two-letter codes according to the country of origin as follows: Colombia (Co), Brazil (Br) and Honduras (Hn), followed by two numerical digits. Subsequently, DNA was purified using the PureLink Genomic DNA Mini Kit (Life Technologies, USA), according to the manufacturer's instructions. DNA samples were tested by real-time quantitative PCR (qPCR) to confirm infection with $P$. vivax and rule out $P$. falciparum co-infection as previously described [25].

\section{Amplification and sequencing of the Pvs48/45 gene in parasite samples from Latin America}

Pvs48/45F (5'-GGAATAATTTCGACCACTC-3') and Pvs 48/45R (5' - TCAGAAGTACAACAGGAG-3') primers were designed to amplify the Pvs48/45 gene coding region (CDS annotation $1357 \mathrm{bp}$ ) from the pvs48/45 of 
Table 1 Origin of Latin American isolates used for pvs48/45 sequencing

\begin{tabular}{lllr}
\hline Country & Department & Locality & N \\
\hline Brazil & Amazonas & Manaus & 14 \\
Honduras & El Paraiso & Moroceli & 1 \\
& Olancho & Catacamas & 2 \\
& & Juticalpa & 1 \\
& Francisco Morazan & Talanga & 2 \\
& & Tegucigalpa (CMDC) & 2 \\
& Gracias a Dios & Pto. Lempira & 1 \\
& & Wampusirpi & 2 \\
Colombia & Cordoba & Tierralta & 10 \\
& Nariño & Tumaco & 10 \\
& Valle del Cauca & Buenaventura & 8 \\
& Choco & Quibdó & 7 \\
\hline
\end{tabular}

Salvador I strain (PlasmoDB Id: PVX_083235). Amplification was performed in $25 \mu \mathrm{L}$ reactions containing 2-4 $\mu \mathrm{L}$ genomic DNA, $500 \mathrm{nM}$ of primers Pvs $48 / 45 \mathrm{~F}$ and Pvs48/45R, and 0.5 units of HotStar HiFidelity Polymerase (QIAGEN, Valencia, CA, USA). Thermal cycling conditions were as follows: initial denaturation for $5 \mathrm{~min}$ at $94{ }^{\circ} \mathrm{C}$, followed by 39 cycles of: $94{ }^{\circ} \mathrm{C}$ for $30 \mathrm{~s}, 55^{\circ} \mathrm{C}$ for $1 \mathrm{~min}, 72{ }^{\circ} \mathrm{C}$ for $2 \mathrm{~min}$, and a final extension step at $72{ }^{\circ} \mathrm{C}$ for $10 \mathrm{~min}$. Amplification products were analysed by gel electrophoresis in $1.2 \%$ agarose gels and purified using the High Pure PCR product purification kit, according to the manufacturer's recommendations (Roche Diagnostics, Mannheim, Germany). Purified PCR products were sequenced using the Big Dye Terminator Kit v3.1 (Applied Biosystems, Austin, TX, USA) in an ABI-PRISM Avant 3100 Automatic Genetic Analyzer (Applied Biosystems, Foster City, CA, USA) using primers Pvs48/45F and Pvs48/45R. Each purified product was sequenced in both directions by a minimum of two independent sequencing reactions until quality base calling value scores $>20$ (predictive sequencing error rate per base of $1.00 \%$ ) were obtained [26], as assessed with the Sequencing Analysis Software v.5.3 (Applied Biosystems).

\section{Sequence assembling, alignment and statistical analysis}

All sequences were assembled against the Sal I $P$. vivax pvs $48 / 45$ sequence reported in PlasmoDB (accession No. PVX_083235) using the reference assembler algorithm in Geneious 4.8.4 [27] and corrections made by manual inspection. The primers sequences were removed before the analysis. Consensus sequences were aligned using the Geneious alignment algorithm and the alignment was used to calculate the number of segregating sites $(\mathrm{S})$, singleton sites, singleton variable (SV) sites, parsimony informative (PI) sites, haplotype diversity $(\mathrm{Hd})$, nucleotide diversity ( $\pi$ ), and the average number of pairwise nucleotide differences within the population $(K)$, number of synonymous (dS) and non-synonymous $(\mathrm{dN})$ substitutions with DnaSP 5.10 package using the JukesCantor model. DNA polymorphism was analysed with a sliding window of 100 bases and a step of 25 bases for a haploid genome [28]. To determine the influence of the geographical origin of the isolates on nucleotide diversity and DNA polymorphism, the same analysis discriminating between groups of samples from Brazil, Colombia and Honduras was performed. Output data were exported to Excel to plot overlapping $\pi$ curves with standardized scales for the different groups. Numbers of synonymous $(\mathrm{dS})$ and non-synonymous $(\mathrm{dN})$ substitutions were compared by a two-tailed $\mathrm{Z}$ test $(\mathrm{P}<0.05)$ using MEGA 6.06 [29] using the Nei and Gojobori's method [30] with the Jukes-Cantor correction and its standard deviation determined by 1000 boot-strap replications [31]. Null hypothesis was $\mathrm{dS}=\mathrm{dN}$, thus indicating that the observed polymorphism was neutral.

\section{Phylogenetic and epitope conservation analysis}

Tajima's D test and Fu and Li's D and F tests using Plasmodium knowlesi pvs48/45 as an outgroup were performed on DNASP 5.10 to test for the neutral theory of evolution. Haplotypes reported in this study were compared to 132 pvs $48 / 45$ sequences reported in GenBank for South Korea [17], North Korea [18], India and Indonesia [18], and reference sequences from Brazil, India, Mauritania, and North Korea and Sal I, same as described above, for a total of 252 isolates. In silico translated DNA sequences were aligned to the $P f s 48 / 45$ 3D7 amino acid sequence (PFD3D7_1346700) to ensure the localization of the single nucleotide polymorphisms (SNPs) in the Cys-rich domains (CRD) I, II, and III were epitopes I, II, III and V as previously reported [12]. Phylogenetic analysis was performed with the 60 sequences reported in this study, and with the 49 sequences reported in GenBank.

\section{Immune epitope mapping}

In order to determine the presence of linear B cell epitopes in the Pvs $48 / 45$ protein sequence and the possible influence of the SNP in the predicted epitopes, an in silico analysis of the entire sequence was performed. Epitopes were predicted based on hydrophilicity, accessibility, polarity, flexibility estimation, combined with secondary structure analysis (Kolaskar-Tongaonkar antigenicity prediction methods) [32].

\section{Molecular modelling of the 3D structure}

Structural models of Pvs48/45 domains were built by using homology-based modelling. The known 3D structures of homologous proteins $P f 12$ from P. falciparum 
[33] and the immunodominant surface antigen from Toxoplasma gondii (Protein Data Bank IDs: 2YMO:A and 1KZQ:A) were used as templates. Sequence alignments were obtained by using a HHpred server [34], ClustalW program [35] and manual adjustment. Structural models were built using the HOMOLOGY module of Insight II program [36]. Resulting structures were subjected to energy minimization using the procedure implemented in the Discovery sub-routine of Insight II.

\section{Results}

\section{Genetic polymorphism and amino acid changes}

Results of the qPCR assay indicated that all samples were specific for $P$. vivax infections. PCR amplification of the Pvs48/45 gene-coding region showed a single band of $\sim 1.3 \mathrm{~kb}$ in all samples, indicating an absence of size polymorphism. Comparison of the nucleotide sequences against the $p v s 48 / 45$ reference sequence (Sal I) showed that SNPs occurred at 15 positions. Nine of these mutations resulted in amino acid changes (non-synonymous substitutions) at positions E35K, Y196H, H211N, K250N, D335Y, E353Q, A376T, K390T, and K418R (Fig. 1a), while the remaining six had no amino acid variations (synonymous substitutions). Of the nine sites, two (H211N, $\mathrm{K} 250 \mathrm{~N})$ were found worldwide, four in Asian isolates (E35K, D335Y, A376T, K418R), while the remaining three were country-specific (Y196H Thailand, K390T Peru, E353Q in Mexico, Peru and Colombia).

\section{Pvs48/45 gene haplotypes}

Based on sequence analysis, the pvs48/45 sequences were classified into seven haplotypes (haplotypes I-VII), in which three resulted from trimorphic polymorphisms, two from dimorphic polymorphisms, and one from a single polymorphism. None of these substitutions was common in all isolates. The amino acid substitution E353Q was found in haplotypes I-IV. The K250N substitution was found in haplotypes I, II, IV, V, and VII, while the H211N amino acid substitution was found in haplotypes I and V. Amino acid substitutions A108T, P264H, N324S, and K370N were only found in haplotypes IV, VI, VII, and $\mathrm{V}$, respectively (Table 2).

\section{Global diversity of $p v s 48 / 45$}

Comparison of $p v s 48 / 45$ polymorphic positions found in LA countries (Brazil, Colombia and Honduras) with the nine polymorphic positions reported for South Korea, North Korea, India and Indonesia showed a set of amino acid substitutions exclusively present among LA isolates. This set contained the substitution E353Q, which is the most frequent among LA isolates (41.9\%), together with the less frequent substitutions T108A (2.3\%), P264H
(2.3\%), N324S (2.3\%), and K370N (2.3\%). On the contrary, D335Y, which is highly conserved among Asian isolates (95.5\%), was not detected among LA isolates. Amino acid variations $\mathrm{H} 211 \mathrm{~N}$ and $\mathrm{K} 250 \mathrm{~N}$ are found in both Asian and LA isolates. These two substitutions, highly conserved among Asian isolates (98.5 and $100 \%$, respectively) were only found in 18.6 and $39.5 \%$ of $P$. vivax LA isolates, respectively. Other substitutions previously reported for Asian isolates [17, 18]: K26R (1.5 \%), E35K (62.1 \%), A367T (95.5 \%), I380T (19.7 \%), K418R (95.5\%) were not found in the present study. As a result, the number of haplotypes for worldwide samples was 18 (Table 3). There was variation of haplotype diversity geographically: low in North Korea, Peru and Mexico, and higher in Myanmar and Colombia. Nucleotide diversity $(\pi)$ was 0.00173 for worldwide samples, ranging between 0.00058 and 0.00216 (Table 3). In Myanmar and Colombia $\pi$ was relatively high, whereas it was low in Mexico, Peru and South Korea. A sliding window plot of $\pi$ revealed a peak at nucleotide positions $1000-1160$ in the CRD-3 region where four of the nine amino acid changes observed in Pvs48/45 occurred (Fig. 1b). The $\pi$ of $P v 48 / 45$ in worldwide samples was at least one order of magnitude lower than that of known blood-stage antigen genes, such as $p v m s p 1$, pvmsp3a and $p v d b p$ (Fig. 2).

\section{Geographic distribution of vs48/45 haplotypes among LA isolates}

The wild-type (Sal I-like) haplotype predominated among Brazilian (92\%), Peruvian (90\%), Mexican (87\%), and Honduran $(71 \%)$ isolates, however in Colombian isolates, it was the second-most frequent haplotype (24\%). Colombian isolates showed a major presence of haplotype I (52 \%), which was less frequent in Honduran isolates (14\%), and not detected among Brazilian, Peruvian and Mexican samples. Haplotype VI, the most frequent in Myanmar and Thailand, was found only among Colombian isolates, whereas haplotype VII was only present in Colombia isolates. Colombia showed the greatest haplotype diversity $(0.841 \pm 0.024)$ with eight non-Sal I haplotypes circulating in the country.

\section{Mapping of immune epitopes}

A total of 12 linear epitopes were identified in regions 1, 5,6 , and 12 , displaying greater algorithmic scores predictive of putative antigenic peptides (Table 4). A high score indicates maximum probability of immunogenicity in the host. Four of the 12 predicted regions contained polymorphic amino acids, however mutations were located in less antigenic epitopes. These substitutions did not affect the epitope prediction, and had limited impact on the calculated antigenic score (e.g., region 7, 1.154 vs 1.153). 


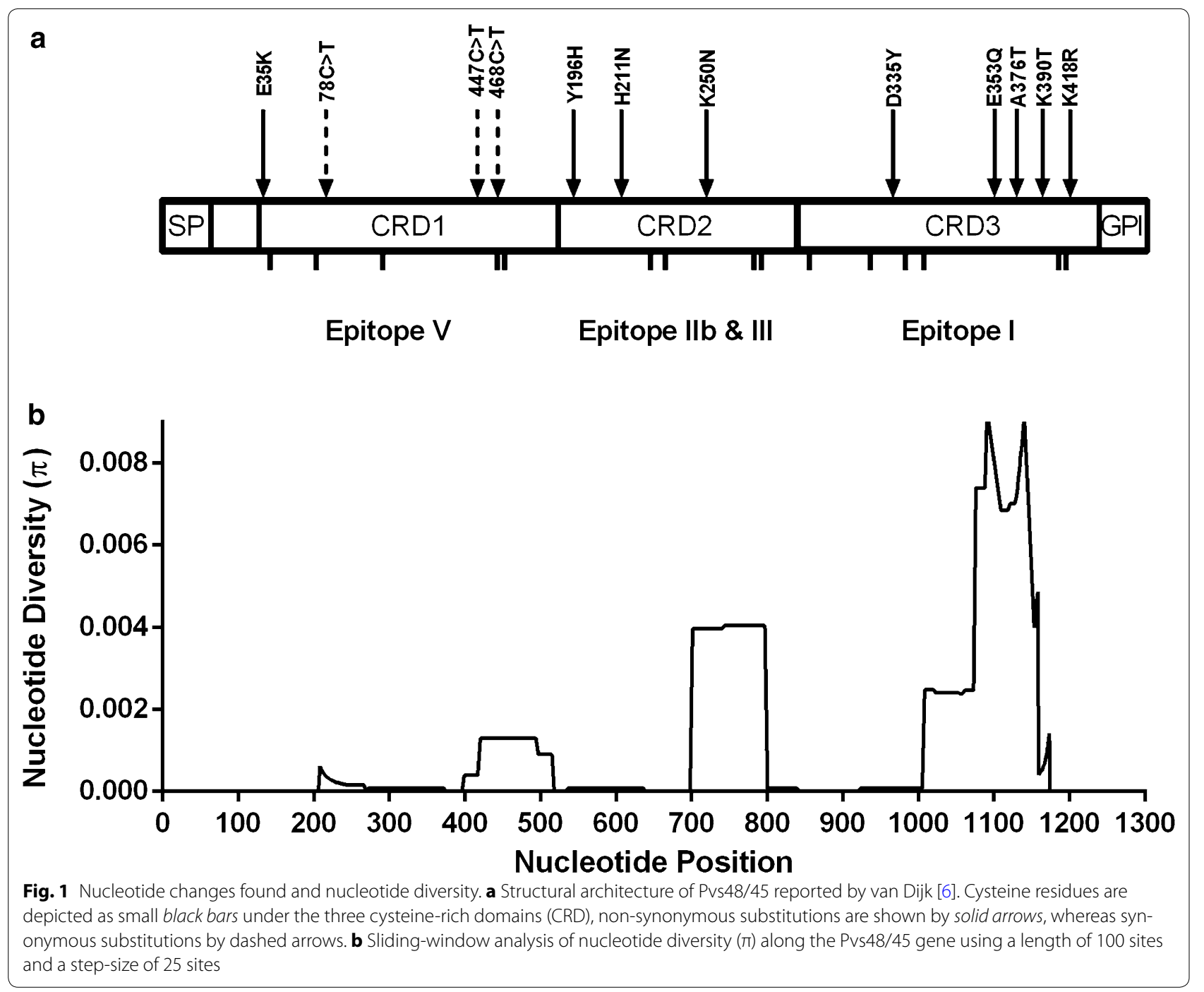

Table 2 Amino acid changes found in the seven pvs48/45 haplotypes in Latin American isolates

\begin{tabular}{|c|c|c|c|c|c|c|c|c|c|}
\hline & \multicolumn{7}{|c|}{ Amino acid position } & \multirow[t]{2}{*}{$\mathrm{n}$} & \multirow[t]{2}{*}{ Frequency (\%) } \\
\hline & 108 & 211 & 250 & 264 & 324 & 353 & 370 & & \\
\hline Sal I & T & $\mathrm{H}$ & K & P & N & $\mathrm{E}$ & K & 68 & 25.1 \\
\hline । & - & N & $\mathrm{N}$ & - & - & Q & - & 35 & 12.9 \\
\hline$\|$ & - & - & N & - & - & Q & - & 9 & 3.3 \\
\hline III & - & - & - & - & - & Q & - & 2 & 0.7 \\
\hline IV & $A$ & - & $\mathrm{N}$ & - & - & Q & - & 4 & 1.5 \\
\hline V & - & $\mathrm{N}$ & $\mathrm{N}$ & - & - & Q & $\mathrm{N}$ & 83 & 30.6 \\
\hline $\mathrm{VI}$ & - & - & - & $\mathrm{H}$ & - & - & - & 64 & 23.6 \\
\hline VII & - & - & $\mathrm{N}$ & - & S & - & - & 6 & 2.2 \\
\hline
\end{tabular}

SNPs location on 3D Pvs48/45 domain structure A 3D model of Pvs48/45 was generated to understand the potential structure-function relationship of the nine polymorphic amino acids under balancing selection. SNPs were located in different regions of Pvs48/45: $\mathrm{H} 211 \mathrm{~N}$ (18.6 \%) was in an intervening region between 
Table 3 Estimates of DNA sequence polymorphism and tests of neutrality for pvs48/45

\begin{tabular}{llllllllllll}
\hline Country & Total isolates & SV sites & PI sites & \# Mutations & $\boldsymbol{K}$ & $\mathbf{H}$ & $\mathbf{H d} \pm \mathbf{S D}$ & $\boldsymbol{\pi} \pm \mathbf{S D}$ & $\mathbf{d N}$ & $\mathbf{d S}$ & Reference \\
\hline Mexico & 15 & 0 & 2 & 2 & 0.441 & 2 & $0.221 \pm 0.121$ & $0.00033 \pm 0.00033$ & 0.00042 & 0.00000 & This study \\
Honduras & 12 & 3 & 2 & 5 & 1.128 & 4 & $0.445 \pm 0.170$ & $0.00123 \pm 0.00094$ & 0.00136 & 0.00077 & This study \\
Colombia & 60 & 3 & 4 & 7 & 1.929 & 9 & $0.841 \pm 0.024$ & $0.00188 \pm 0.00073$ & 0.00185 & 0.002 & This study \\
Peru & 24 & 1 & 2 & 3 & 0.372 & 3 & $0.218 \pm 0.103$ & $0.00034 \pm 0.00046$ & 0.00045 & 0.00000 & This study \\
Brazil & 13 & 2 & 1 & 3 & 0.59 & 4 & $0.526 \pm 0.153$ & $0.00058 \pm 0.00062$ & 0.00019 & 0.00194 & This study \\
Latin America & 124 & 3 & 5 & 8 & 1.228 & 11 & $0.610 \pm 0.047$ & $0.00168 \pm 0.00087$ & 0.00176 & 0.00151 & This study \\
Myanmar & 8 & 2 & 5 & 7 & 2.722 & 5 & $0.889 \pm 0.071$ & $0.00216 \pm 0.00110$ & 0.00282 & 0.0000 & This study \\
Thailand & 18 & 5 & 4 & 9 & 1.392 & 5 & $0.484 \pm 0.138$ & $0.00116 \pm 0.00101$ & 0.00103 & 0.00085 & This study \\
South Korea & 86 & 0 & 2 & 2 & 0.716 & 3 & $0.611 \pm 0.026$ & $0.00053 \pm 0.00004$ & 0.00069 & 0.00000 & {$[17]$} \\
North Korea & 46 & 2 & 7 & 9 & 1.987 & 5 & $0.0018 \pm 0.042$ & $0.00147 \pm 0.00069$ & 0.00029 & 0.00186 & {$[18]$} \\
Worldwide & 282 & 7 & 5 & 12 & 1.047 & 15 & $0.686 \pm 0.00149$ & $0.00173 \pm 0.00149$ & 0.00188 & 0.00149 & This study \\
\hline
\end{tabular}

SV singleton variable, $\mathrm{Pl}$ parsimony informative, $K$ average number of pair-wise differences, $\mathrm{H}$ number of haplotypes, $\mathrm{Hd}$ haplotype diversity, $\pi$ observed average pairwise nucleotide diversity, $\mathrm{dN}$ number of non-synonymous substitutions, dS number of synonymous substitutions

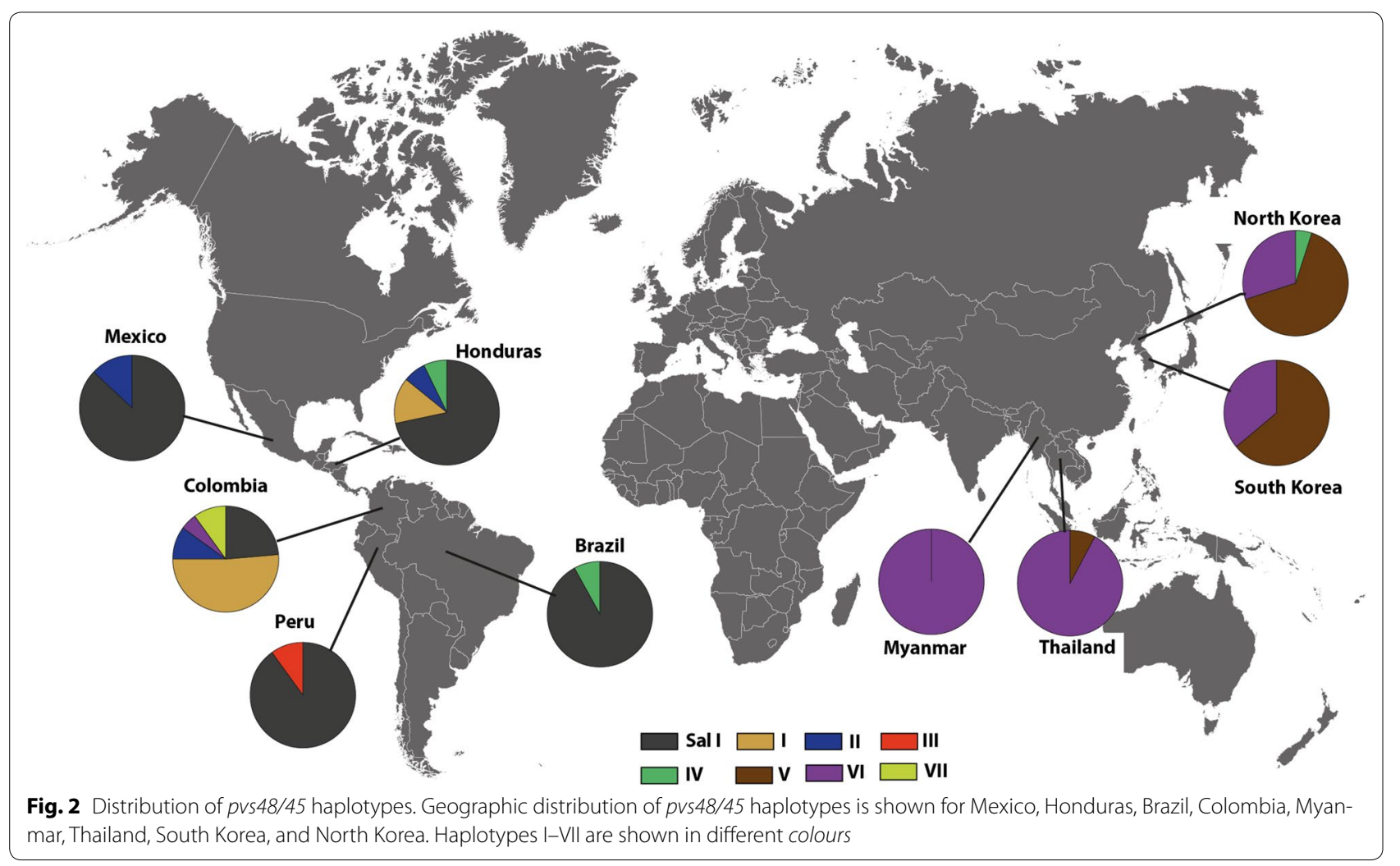

domains 1 and 2; K250N (39.5\%) was located in domain CRD-2, which is not considered a six-cys domain; and E353Q (41.9 \%), A376T (50.7 \%), K390T (1.1 \%), and $\mathrm{K} 418 \mathrm{R}(51.7 \%)$ in domain CRD-3, which is the nearest to the trans-membrane region (Fig. 3). Mapping of the SNPs that led to amino acid substitutions onto the Pvs48/45 3D model domains showed that these residues are located in the loop regions.

\section{Discussion}

This study showed a limited $p v s 48 / 45$ genetic diversity in a total of $282 P$. vivax isolates worldwide. Only 18 amino acid substitutions were found within the entire protein sequence of an estimated 450 amino acid residues. Plasmodium vivax sequences corresponded to isolates from nine distant countries in three continents. Two pvs $48 / 45$ haplotypes were found to be shared by Asian and LA 
Table 4 Potential antigenic determinants for the Pvs48/45

\begin{tabular}{lccllll}
\hline \# Antigenic region & AA start & AA end & Length & Score & Polymorphism & Sequence $^{\text {a }}$ \\
\hline 1 & 4 & 19 & 16 & 1.235 & None & RQLANLLLVLSLLRGI \\
2 & 46 & 64 & 19 & 1.083 & None & GFKCNFSSKGVHNLEPILT \\
3 & 66 & 90 & 25 & 1.197 & None & KRSLVCSIYSYFIYDKIKLTIPKKI \\
4 & 99 & 109 & 11 & 1.129 & None & PEKCFQTVYTN \\
5 & 165 & 189 & 25 & 1.206 & None & ISNVKGRVALVQVNVLKYPHKITSI \\
6 & 220 & 237 & 18 & 1.228 & None & GELVVLACEKVDDKCFKK \\
7 & 242 & 304 & 63 & 1.154 & K250N & SPLSLYKSKKIVYHKNLSIFKAPVYVKSADVTAECSCNVDSTIYTLSLKPVYT \\
8 & 326 & 341 & 16 & 1.138 & D335Y & QITCSIELVDTSYNHL \\
9 & 347 & 361 & 15 & 1.167 & E353Q & PGEVLPECFFQVYQR \\
10 & 366 & 377 & 12 & 1.141 & A376T & LEPSKIVYLDAQ \\
11 & 394 & 404 & 11 & 1.152 & None & IVKIFGLVGSI \\
12 & 422 & 447 & 26 & 1.255 & None & YMSVKIAAGYFGFLAKIFILLIVLLL \\
\hline
\end{tabular}

a Italics AA indicates Cysteine residues, whereas Bold italics AA represent the location of polymorphic sites

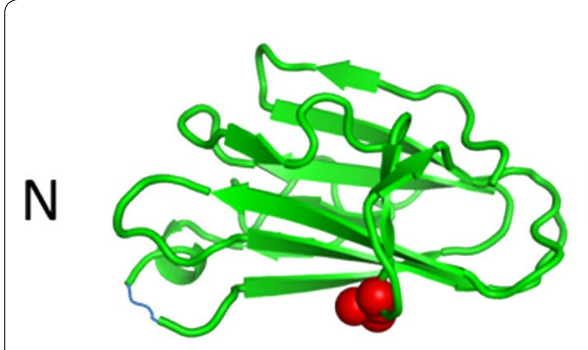

CRD1

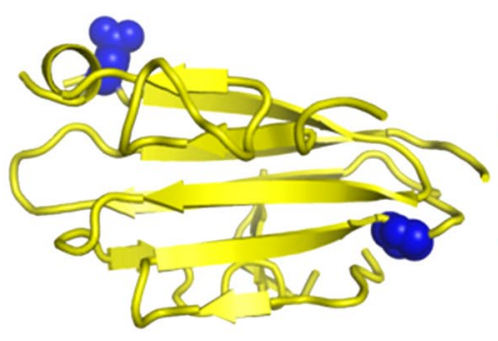

CRD2

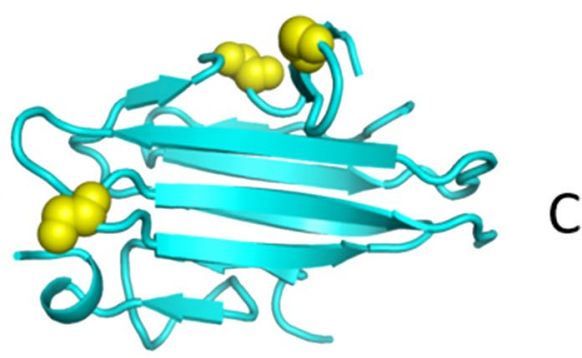

CRD3

Fig. 3 A ribbon representation of 3D models of the Pvs48/45 domains. Space-filling representation of amino-acid side chains (red, blue and yellow balls) denotes the locations of the non-synonymous amino acid substitutions in the three cysteine-rich domains (CRD)

parasites, with a strong geographical allele clustering. Recent studies on the diversity of $p v s 48 / 45$ among $P$. vivax isolates circulating in the Korean peninsula, China and Thailand showed low levels of genetic diversity [17, 18, 21, 37]; likewise, Brazilian isolates showed almost no variation when compared to the Sal I reference strain (PVX_083235), originally from El Salvador.

Interestingly, Korean, Colombian and Honduran isolates displayed limited sequence polymorphism. Pvs48/45 nucleotide and amino acid substitutions in isolates from Korea were found at pre-CRD (E35K), CRD-2 (H211N and K250N) and CRD-3 (D335Y, A376T, I380T, K418R). Pvs48/45 was more conserved in the Korean populations where nucleotide diversity varied from 0.00053 [17] to $0.00147[17,18]$, and the haplotypes V was unique for these populations. Plasmodium vivax was recently re-introduced into the peninsula of Korea with a rapid spread pattern, suggestive of a high genetic diversity [38]. This could explain the greater $p v s 48 / 45$ variability observed in Korean isolates as compared to isolates from Honduras and Mexico, and the almost absent variability among Brazilian isolates Despite the variability in the Korean isolates, globally, Pvs48/45 remains a highly conserved antigen compared to other transmissionblocking vaccine candidates.

Results are in agreement with previous observations that transmission-blocking vaccine candidate antigens Pvs25, Pvs28, Pvs48/45, and PvWARP showed limited sequence polymorphisms [18]. More importantly, the limited polymorphism found here does not appear to affect the immunogenicity of predicted epitopes as only three of nine amino acid substitutions in isolates from Colombia and Honduras were located at CRD2 (H211N and $\mathrm{K} 250 \mathrm{~N}$ ) and CRD3 (E353Q). No substitutions were observed in CRD1, in agreement with reports for Korean isolates and for P. falciparum in Kenyan, Thai, Indian, and Venezuelan isolates [39, 40]. However, further studies are required to confirm the role of these $\mathrm{B}$ cell epitopes and to identify $\mathrm{T}$ cell epitopes in defining the potential of Pvs48/45 as a transmission-blocking vaccine candidate. 
Pvs48/45 Cys domains are important for proper conformation of immune epitopes $[8,45]$. In Pfs $48 / 45$, four epitopes designated epitope V (CRD1), epitope IIb (CRD2), epitope III (CRD2), and epitope I (CRD3) have been described previously [8]. The N-terminal CRD2 and CRD3 epitopes appear to be transmission-blocking targets as specific monoclonal antibodies to these regions have demonstrated an ability to prevent parasite fertilization, and consequently mosquito infection $[12,46]$.

Substitutions $\mathrm{H} 211 \mathrm{~N}$ and $\mathrm{K} 250 \mathrm{~N}$ are predicted to be located in loop regions [18], which could serve as potential vaccine targets. Interestingly, no amino acid substitutions were found in any of the Cys residues of Pvs48/45 in the present study, which are critical for proper presentation of the transmission-blocking epitopes [12]. However, an amino acid substitution (E353Q) was found next to a Cys residue reported to be involved in a disulfide bond. The influence of this variation on the formation of the disulfide bridge is yet to be explored.

Although parasite antigen diversity has been explained in part by immune pressure on the parasite [41-43], it does not appear to apply to Pvs48/45 as the protein is highly immunogenic, and it is expressed during the entire gametocyte maturation process. For $P$. vivax sexual antigens the exposure to the immune system could be longer than in $P$. falciparum due to the early appearance of $P$. vivax gametocytes in circulation [44]. However it does not appear to apply to Pvs48/45 as the protein is conserved and highly immunogenic under natural conditions.

Transmission-blocking vaccines have been considered a promising strategy/tool for malaria control/elimination. In $P$. vivax malaria it has been observed that gametocytogenesis occurs earlier than in P. falciparum and remains active even in asymptomatic carriers [44]. Consequently, malaria transmission to mosquitoes is likely to be more efficient, and thus, transmission-blocking vaccines would have a greater impact [47].

\section{Conclusions}

There is limited sequence polymorphism in pvs $48 / 45$ with noted geographical clustering among Asian and American isolates. The low genetic diversity of the protein does not influence the predicted antigenicity or protein structure and, therefore, supports its further development as a transmission-blocking vaccine candidate with widespread global potential.

\section{Authors' contributions}

$\mathrm{SH}$ and MA conceived and designed the study; $\mathrm{NM}, \mathrm{AV}$ and $\mathrm{SH}$ wrote the manuscript; NM and AT performed the laboratory work. AK performed structural modelling of Pvs48/45. ML and JA contributed reagents/materials/ analytical tools. All authors critically revised the manuscript. All authors read and approved the final manuscript.

\section{Author details}

${ }^{1}$ Malaria Vaccine and Drug Development Center, Cali, Colombia. ${ }^{2}$ Facultad de Ciencias Médicas, Hospital Escuela Universitario, Universidad Nacional Autónoma de Honduras, Tegucigalpa, Honduras. ${ }^{3}$ Fundação de Medicina Tropical Dr. Heitor Vieira Dourado, Manaus, Brazil. ${ }^{4}$ Centre de Recherches Biochimie Macromoléculaire (CRBM), Institut de Biologie Computationnelle (IBC), CNRS, University of Montpellier, Montpellier, France. ${ }^{5}$ Institute of Bioengineering, University ITMO, Saint Petersburg, Russia. ${ }^{6}$ Caucaseco Scientific Research Center, Cali, Colombia. ${ }^{7}$ School of Health, Universidad del Valle, Cali, Colombia.

\section{Acknowledgements}

The authors thank the communities of the endemic areas of Brazil, Honduras and Colombia that participated in this study. Special thanks to Miguel Angel Hernandez for his technical assistance and Yoldy Benavides for statistical support. This work was supported by NIAID (Research Grant U19AI089702 and 1 R01Al12123701) and Colciencias (Grant Contracts 360-2011, 685-2013 and 719-2013)

\section{Competing interests}

The authors declare that they have no competing interests.

Received: 19 January 2016 Accepted: 31 March 2016

Published online: 12 April 2016

\section{References}

1. Lacerda MV, Fragoso SC, Alecrim MG, Alexandre MA, Magalhães BM, Siqueira AM, et al. Postmortem characterization of patients with clinical diagnosis of Plasmodium vivax malaria: to what extent does this parasite kill? Clin Infect Dis. 2012;55:e67-74.

2. Mendis K, Sina BJ, Marchesini P, Carter R. The neglected burden of Plasmodium vivax malaria. Am J Trop Med Hyg. 2001;64:97-106.

3. malERA Consultative Group on Vaccines. A research agenda for malaria eradication: vaccines. PLoS Med. 2011;8:e1000398.

4. Birkett AJ, Moorthy VS, Loucq C, Chitnis CE, Kaslow DC. Malaria vaccine R\&D in the Decade of Vaccines: breakthroughs, challenges and opportunities. Vaccine. 2013;31(Suppl 2):B233-43.

5. Carter R. Transmission blocking malaria vaccines. Vaccine. 2001;19:2309-14

6. van Dijk MR, Janse CJ, Thompson J, Waters AP, Braks JA, Dodemont HJ, et al. A central role for $\mathrm{P} 48 / 45$ in malaria parasite male gamete fertility. Cell. 2001;104:153-64.

7. Carter R, Coulson A, Bhatti S, Taylor BJ, Elliott JF. Predicted disulfidebonded structures for three uniquely related proteins of Plasmodium falciparum, Pfs230, Pfs48/45 and Pf12. Mol Biochem Parasitol. 1995;71:203-10.

8. Gerloff DL, Creasey A, Maslau S, Carter R. Structural models for the protein family characterized by gamete surface protein Pfs 230 of Plasmodium falciparum. Proc Natl Acad Sci USA. 2005;102:13598-603.

9. Arévalo-Herrera M, Vallejo AF, Rubiano K, Solarte Y, Marin C, Castellanos A, et al. Recombinant Pvs 48/45 antigen expressed in E. coli generates antibodies that block malaria transmission in Anopheles albimanus mosquitoes. PLoS ONE. 2015;10:e0119335.

10. Ong C, Zhang K, Eida S, Graves P, Dow C, Looker M, et al. The primary antibody response of malaria patients to Plasmodium falciparum sexual stage antigens which are potential transmission blocking vaccine candidates. Parasite Immunol. 1990;12:447-56.

11. Riley E, Ong C, Olerup O, Eida S, Allen S, Bennett S, et al. Cellular and humoral immune responses to Plasmodium falciparum gametocyte antigens in malaria-immune individuals. Limited response to the 48/45-kilodalton surface antigen does not appear to be due to $\mathrm{MHC}$ restriction. J Immunol. 1990;144:4810-6.

12. Outchkourov N, Vermunt A, Jansen J, Kaan A, Roeffen W, Teelen K, et al. Epitope analysis of the malaria surface antigen pfs48/45 identifies a subdomain that elicits transmission blocking antibodies. J Biol Chem. 2007;282:17148-56.

13. Roeffen WF, Raats JM, Teelen K, Hoet RM, Eling WM, van Venrooij WJ, et al. Recombinant human antibodies specific for the Pfs $48 / 45$ protein of the malaria parasite Plasmodium falciparum. J Biol Chem. 2001;276:19807-11. 
14. Vermeulen AN, Roeffen WF, Henderik JB, Ponnudurai T, Beckers PJ, Meuwissen JH. Plasmodium falciparum transmission blocking monoclonal antibodies recognize monovalently expressed epitopes. Dev Biol Stand. 1985;62:91-7.

15. Tsuboi T, Kaslow DC, Gozar MM, Tachibana M, Cao YM, Torii M. Sequence polymorphism in two novel Plasmodium vivax ookinete surface proteins, Pvs25 and Pvs28, that are malaria transmission-blocking vaccine candidates. Mol Med. 1998;4:772-82.

16. Feng $H$, Zheng $L$, Zhu $X$, Wang G, Pan Y, Li Y, et al. Genetic diversity of transmission-blocking vaccine candidates Pvs 25 and Pvs28 in Plasmodium vivax isolates from Yunnan Province, China. Parasit Vectors. 2011;4:224.

17. Kang JM, Ju HL, Moon SU, Cho PY, Bahk YY, Sohn WM, et al. Limited sequence polymorphisms of four transmission-blocking vaccine candidate antigens in Plasmodium vivax Korean isolates. Malar J. 2013;12:144.

18. Woo MK, Kim KA, Kim J, Oh JS, Han ET, An SS, et al. Sequence polymorphisms in Pvs48/45 and Pvs47 gametocyte and gamete surface proteins in Plasmodium vivax isolated in Korea. Mem Inst Oswaldo Cruz. 2013;108:359-67, pii: S0074-02762013000300359.

19. Alexandre MA, Ferreira CO, Siqueira AM, Magalhaes BL, Mourao MP, Lacerda MV, et al. Severe Plasmodium vivax malaria, Brazilian Amazon. Emerg Infect Dis. 2010;16:1611-4.

20. Chaparro P, Padilla J, Vallejo AF, Herrera S. Characterization of a malaria outbreak in Colombia in 2010. Malar J. 2013:12:330.

21. Tachibana M, Suwanabun N, Kaneko O, Iriko H, Otsuki H, Sattabongkot J, et al. Plasmodium vivax gametocyte proteins, Pvs48/45 and Pvs47, induce transmission-reducing antibodies by DNA immunization. Vaccine. 2015;33:1901-8.

22. Broad Institute [https://www.broadinstitute.org/].

23. Luo Z, Sullivan SA, Carlton JM. The biology of Plasmodium vivax explored through genomics. Ann NY Acad Sci. 2015;1342:53-61.

24. Miller SA, Dykes DD, Polesky HF. A simple salting out procedure for extracting DNA from human nucleated cells. Nucleic Acids Res. 1988;16:1215.

25. Rougemont M, Van Saanen M, Sahli R, Hinrikson HP, Bille J, Jaton K. Detection of four Plasmodium species in blood from humans by $18 \mathrm{~S}$ rRNA gene subunit-based and species-specific real-time PCR assays. J Clin Microbiol. 2004;42:5636-43.

26. Le H, Hinchcliffe M, Yu B, Trent RJ. Computer-assisted reading of DNA sequences. Clin Bioinform. 2008;141:177-97.

27. Kearse M, Moir R, Wilson A, Stones-Havas S, Cheung M, et al. Geneious basic: an integrated and extendable desktop software platform for the organization and analysis of sequence data. Bioinformatics. 2012;28:1647-49.

28. Librado P, Rozas J. DnaSP v5: a software for comprehensive analysis of DNA polymorphism data. Bioinformatics. 2009;25:1451-2.

29. Tamura K, Stecher G, Peterson D, Filipski A, Kumar S. MEGA6: molecular evolutionary genetics analysis version 6.0. Mol Biol Evol. 2013;30:2725-9.

30. Nei M, Gojobori T. Simple methods for estimating the numbers of synonymous and nonsynonymous nucleotide substitutions. Mol Biol Evol. 1986:3:418-26.

31. Nei M, Kumar S. Molecular evolution and phylogenetics. Oxford: Oxford University Press; 2000

32. Bryson CJ, Jones TD, Baker MP. Prediction of immunogenicity of therapeutic proteins: validity of computational tools. BioDrugs. 2010;24:1-8.
33. Tonkin ML, Arredondo SA, Loveless BC, Serpa JJ, Makepeace KA, Sundar $\mathrm{N}$, et al. Structural and biochemical characterization of Plasmodium falciparum 12 (Pf12) reveals a unique interdomain organization and the potential for an antiparallel arrangement with Pf41. J Biol Chem. 2013;288:12805-17

34. Soding J, Biegert A, Lupas AN. The HHpred interactive server for protein homology detection and structure prediction. Nucleic Acids Res. 2005;33:W244-8.

35. Thompson JD, Higgins DG, Gibson TJ. CLUSTAL W: improving the sensitivity of progressive multiple sequence alignment through sequence weighting, position-specific gap penalties and weight matrix choice. Nucleic Acids Res. 1994;22:4673-80.

36. Dayringer $\mathrm{H}$, Tramontano A, Sprang S, Fletterick R. Interactive program for visualization and modelling of proteins, nucleic acids and small molecules. J Mol Gr. 1986;4:82-7.

37. Feng H, Gupta B, Wang M, Zheng W, Zheng L, Zhu X, et al. Genetic diversity of transmission-blocking vaccine candidate Pvs48/45 in Plasmodium vivax populations in China. Parasit Vectors. 2015;8:615

38. Choi YK, Choi KM, Park MH, Lee EG, Kim YJ, Lee BC, et al. Rapid dissemination of newly introduced Plasmodium vivax genotypes in South Korea. Am J Trop Med Hyg. 2010;82:426-32.

39. Anthony TG, Polley SD, Vogler AP, Conway DJ. Evidence of non-neutral polymorphism in Plasmodium falciparum gamete surface protein genes Pfs47 and Pfs48/45. Mol Biochem Parasitol. 2007;156:117-23.

40. Escalante AA, Grebert HM, Chaiyaroj SC, Riggione F, Biswas S, Nahlen $\mathrm{BL}$, et al. Polymorphism in the gene encoding the Pfs48/45 antigen of Plasmodium falciparum. XI. Asembo Bay Cohort Project. Mol Biochem Parasitol. 2002;119:17-22.

41. Escalante AA, Lal AA, Ayala FJ. Genetic polymorphism and natural selection in the malaria parasite Plasmodium falciparum. Genetics. 1998;149:189-202.

42. McConkey GA, Waters AP, McCutchan TF. The generation of genetic diversity in malaria parasites. Annu Rev Microbiol. 1990;44:479-98.

43. Neafsey DE, Juraska M, Bedford T, Benkeser D, Valim C, Griggs A, et al. Genetic diversity and protective efficacy of the RTS, S/AS01 malaria vaccine. N Engl J Med. 2015;373:2025-37.

44. Vallejo AF, García J, Amado-Garavito AB, Arévalo-Herrera M, Herrera S. Plasmodium vivax gametocyte infectivity in sub-microscopic infections. Malar J. 2016;15:1.

45. Pradel G. Proteins of the malaria parasite sexual stages: expression, function and potential for transmission blocking strategies. Parasitology. 2007;134:1911-29.

46. Outchkourov NS, Roeffen W, Kaan A, Jansen J, Luty A, Schuiffel D, et al. Correctly folded Pfs48/45 protein of Plasmodium falciparum elicits malaria transmission-blocking immunity in mice. Proc Natl Acad Sci USA. 2008;105:4301-5.

47. Branch O, Casapia WM, Gamboa DV, Hernandez JN, Alava FF, Roncal N, et al. Clustered local transmission and asymptomatic Plasmodium falciparum and Plasmodium vivax malaria infections in a recently emerged, hypoendemic Peruvian Amazon community. Malar J. 2005;4:27.

\section{Submit your next manuscript to BioMed Central and we will help you at every step:}

- We accept pre-submission inquiries

- Our selector tool helps you to find the most relevant journal

- We provide round the clock customer support

- Convenient online submission

- Thorough peer review

- Inclusion in PubMed and all major indexing services

- Maximum visibility for your research

Submit your manuscript at www.biomedcentral.com/submit
() Biomed Central 